\title{
Correction to: Statins, metformin, proprotein-convertase-subtilisin-kexin type-9 (PCSK9) inhibitors and sex hormones: Immunomodulatory properties?
}

\author{
Christian A. Koch ${ }^{1,2,3,4,5} \cdot$ Siegfried Krabbe ${ }^{1,2,6} \cdot$ Bernd Hehmke $^{7}$
}

Published online: 23 March 2019

(C) Springer Science+Business Media, LLC, part of Springer Nature 2019

\section{Correction to: Reviews in Endocrine and Metabolic Disorders (2018) 19:363-395 https://doi.org/10.1007/s11154-018-9478-8}

The authors would like to note that several errors had occurred, especially in Table 2, Tables 5, 6 and 7, Figure 13, and in the legend of Figure 23.

On page 365 , right column, bottom, and on page 366 , left column, top, the sentence should read "....role in the pathogenesis of autoimmune thyroid disease, multiple sclerosis, rheumatoid arthritis, type 1 diabetes, and others."
On page 368, Table 2, left column, under the heading "Criterion" the following typographical errors should be corrected to the vertical column:

Increased frequency.....

Increased responsiveness of IL-10...

Enhancements of upregulated...

The online version of the original article can be found at https://oi.org/ 10.1007/s11154-018-9478-8

\footnotetext{
Christian A. Koch

Christian.koch65@gmail.com

$\triangle$ Bernd Hehmke

hehmke@diabetes-karlsburg.de

Siegfried Krabbe

Dr.siegfried_krabbe@gmx.de

Medicover GmbH Berlin, Berlin, Germany

2 Carl von Ossietzky University, Oldenburg, Germany

3 Technical University of Dresden, Dresden, Germany

4 University of Louisville, Louisville, KY, USA

5 University of Tennessee Health Science Center, Memphis, TN, USA

6 University of Greifswald, Greifswald, Germany

7 Institute of Diabetes “Gerhardt Katsch”, Karlsburg, Germany
} 
Table 7 Effect of the lipid-lowering drug simvastatin on the frequency of proinflammatory Interferon-gamma+ and regulatory IL- $10^{+}$thyroidautoreactive CD4+ T helper cells in patients with autoimmune thyroiditis in comparison to untreated patients and healthy donors

\begin{tabular}{|c|c|c|c|c|c|c|c|}
\hline \multirow[b]{2}{*}{ Group } & \multicolumn{7}{|c|}{ Cytokine phenotype of thyroid-autoreactive $\mathrm{T}$ cells ${ }^{\S}$ (frequency) } \\
\hline & $\operatorname{Tr} 1$ & $\operatorname{Tr} 0$ & Th1 & $\operatorname{Tr} 1+\operatorname{Tr} 0$ & $\operatorname{Tr} 0+\operatorname{Th} 1$ & Tr1+Th1 & $\operatorname{Tr} 1+\operatorname{Tr} 0+\operatorname{Th} 1$ \\
\hline Thyreoiditis, without simvastatin treatment $(n=31)$ & $4.83 \%$ & $7.25 \%$ & $6.34 \%$ & $10.57 \%$ & $2.11 \%$ & $0.30 \%$ & $2.11 \%$ \\
\hline Thyreoiditis, treated with $40 \mathrm{mg} / \mathrm{d}$ simvastatin $(n=7)$ & $10.39 \%$ & $10.39 \%$ & $1.30 \%$ & $19.48 \%$ & $0.00 \%$ & $0.00 \%$ & $0.00 \%$ \\
\hline Healthy donors $(n=29)$ & $8.57 \%$ & $10.15 \%$ & $0.00 \%$ & $8.89 \%$ & $2.54 \%$ & $0.32 \%$ & $0.63 \%$ \\
\hline
\end{tabular}

Data are given as percentage of $\mathrm{T}$ cell cultures with the corresponding cytokine phenotype in relation to the total number of $\mathrm{T}$ cell test cultures

$\S$ Tr1: T regulatory type 1 , IL-10+; Tr0: T regulatory type 0 , IFN- $\gamma+$ IL-10+; Th1: T helper type 1 , IFN- $\gamma+$

${ }^{\circ} p<0.0001$ vs. healthy donors; ${ }^{\mathbf{T}} p=0.032$ vs. thyroiditis without simvastatin; ${ }^{*} p=0.008$ vs. healthy donors; $\chi 2$-test

\section{Graves' Orbitopathy - Immunmodulatoy Therapy}

\section{Statins}

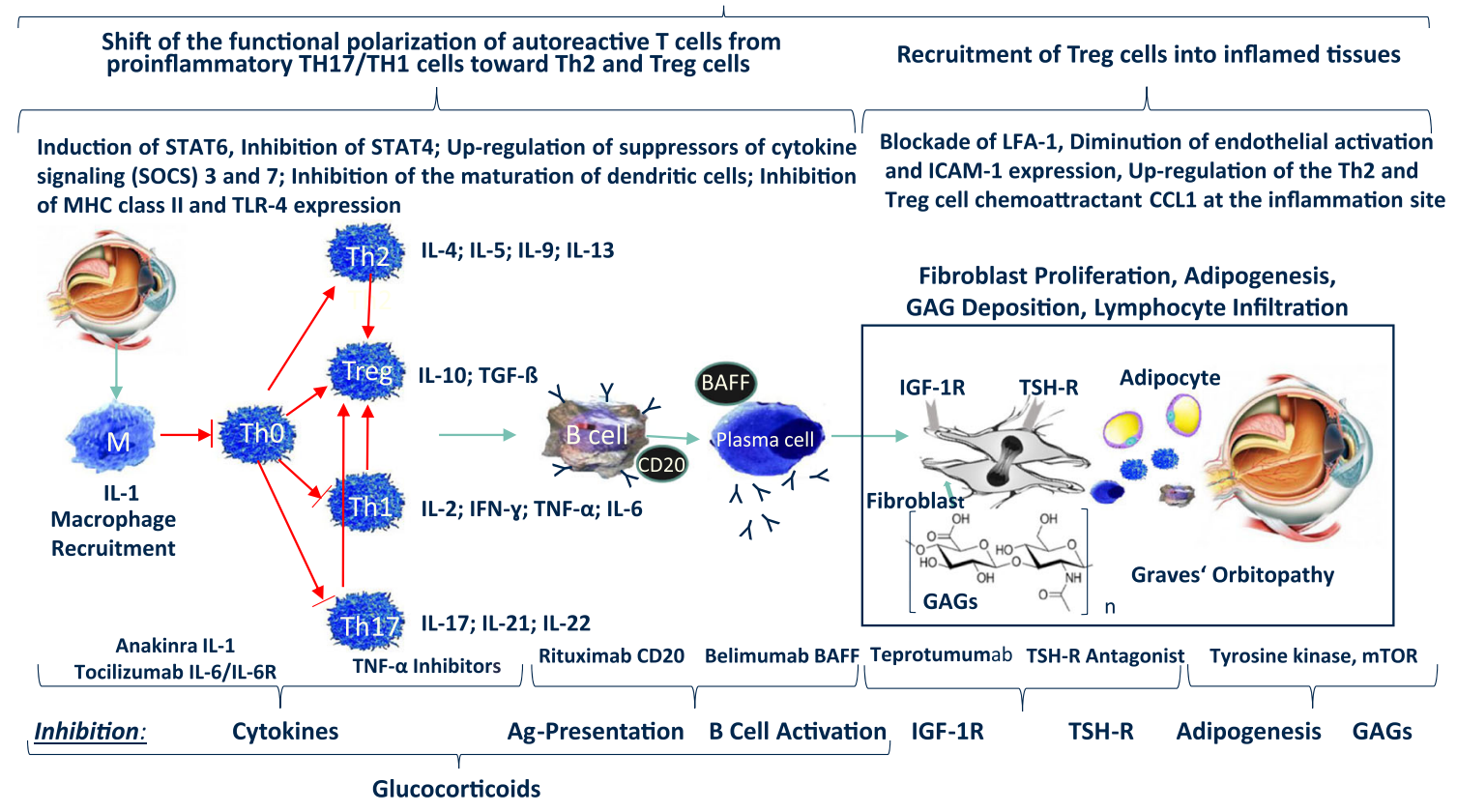

Fig. 13 Statins as immunomodulatory therapy in GO

On page 371, in Figure 13 the blue cell "Th" should be corrected to "Th1".

On page 375 , right column, middle section, the sentence should read "...in Table 8 revealed a statininduced....

On page 386, the legend of Figure 23 at the end of the page should be corrected to "... whereas few unbalanced IL-17+ IFN-gamma+ Th17/Th1 cells responding to peptide 9 were found....
On page 375 in Table 5 and on page 388 in Table 6 "Mal. weight" should be corrected to "Mol. weight".

On page 389, in Table 7 the horizontal line under "Group" should be corrected as well as the table legend, see reprinted Table 7.

Publisher's note Springer Nature remains neutral with regard to jurisdictional claims in published maps and institutional affiliations. 